\title{
LUT
}

Lappeenranta

University of Technology

\section{Alcohol promoted methanol synthesis enhanced by adsorption of water and dual catalysts}

Nieminen Harri, Givirovskiy Georgy, Laari Arto, Koiranen Tuomas

This is a Final draft

version of a publication

published by Elsevier

in Journal of $\mathrm{CO} 2$ Utilization

DOI: $10.1016 /$ j.jcou.2018.01.002

Copyright of the original publication: () 2018 Elsevier Ltd.

Please cite the publication as follows:

Nieminen, H., Givirovskiy, G., Laari, A., Koiranen, T. (2018). Alcohol promoted methanol synthesis enhanced by adsorption of water and dual catalysts. Journal of $\mathrm{CO} 2$ Utilization, Vol. 24, pp. 180-189. DOI: 10.1016/j.jcou.2018.01.002 
1 Alcohol promoted methanol synthesis enhanced by adsorption of water and dual catalysts

2 Harri Nieminen*, Georgy Givirovskiy, Arto Laari, Tuomas Koiranen

3 Lappeenranta University of Technology, Laboratory of Process and Product Development, P.O. Box 20, Fl-53851

$4 \quad$ Lappeenranta, Finland

5 *Corresponding author Tel.: +358 40 7451800, E-mail address: harri.nieminen@lut.fi

\section{Abstract}

7 Alcohol-promoted methanol synthesis uses heterogeneous methanol synthesis catalysts in alcoholic solvents 8 where the alcohols act as a co-catalyst. In the presence of alcohol, the reaction proceeds through alcohol formate 9 ester as an intermediate, allowing methanol synthesis at lower temperatures than conventional gas-phase 10 synthesis. In the present work, alcohol-promoted $\mathrm{CO}_{2}$ hydrogenation to methanol was studied experimentally using 11 a $\mathrm{Cu} / \mathrm{ZnO}$ catalyst with 1-butanol and 2-butanol as solvents. As water is known to inhibit methanol synthesis on $\mathrm{Cu} / \mathrm{ZnO}$ catalysts, the alcohol-promoted process was further developed by in-situ adsorption of water using a $3 \AA$ molecular sieve. The methanol productivity significantly improved as a result of the lowered concentration of water.

14 The concentration of water was thus identified as a key factor affecting the overall methanol productivity. As the alcohol-promoted methanol synthesis process is characterized by two separate reaction steps, the use of separate 16 catalysts optimized for each step offers an interesting approach for the development of this process. Such a dual17 catalysis concept was tested using a copper chromite catalyst together with $\mathrm{Cu} / \mathrm{ZnO}$. Promising results were obtained, as methanol productivity increased with the addition of copper chromite. Catalyst characterization was

19 carried out using XRD and SEM-EDS and potential effects of observed changes in catalyst structure during reaction 20 are discussed.

\section{Keywords}

$22 \mathrm{CO}_{2}$ hydrogenation, methanol synthesis, $\mathrm{Cu} / \mathrm{ZnO}$, liquid-phase, alcohol promoted, dual catalysis, copper chromite, 23 molecular sieve

\section{Conflicts of interest: none}




\section{Introduction}

Development of efficient and flexible energy storage methods is critical for a global shift from a fossil fuels based economy to a renewable energy based economy [1]. The use of surplus peak electricity generated from fluctuating renewable energy sources, such as wind and solar energy, for the production of chemical compounds would enable energy storage in a highly transportable form at high energy density. Generation of hydrogen by electrolysis of water is the common starting point in chemical energy storage strategies [2]. However, due to the difficulties and hazards associated with large-scale storage and transportation of gaseous hydrogen, further utilization of hydrogen for production of carbon-containing liquid fuels and chemical compounds might be preferable.

Methanol is an example of such a potential liquid-phase chemical energy carrier [3]. Methanol is an important and versatile industrial chemical that can also be used as a fuel in power generation and in internal combustion engines and fuel cells [4]. Additionally, methanol is a versatile raw material for synthesis of a variety of chemical products. For instance, methanol can be transformed into gasoline in the methanol-to-gasoline process (MTG) [5] or into olefins in the methanol-to-olefins process (MTO) [6].

Current production of methanol is based on catalytic conversion of synthesis gas generated from fossil sources, commonly natural gas. The syngas is mainly composed of mixtures of hydrogen, carbon monoxide and carbon dioxide. In conventional methanol synthesis, copper and zinc oxide $(\mathrm{Cu} / \mathrm{ZnO})$ catalysts are generally employed at reaction temperatures of $200-300{ }^{\circ} \mathrm{C}$ and pressures of $50-100$ bar [7].

43 The methanol synthesis process can be described by the following three equilibrium reactions:

$$
\mathrm{CO}_{2}+3 \mathrm{H}_{2} \rightleftharpoons \mathrm{CH}_{3} \mathrm{OH}+\mathrm{H}_{2} \mathrm{O} \quad \Delta H^{0}=-49.8 \mathrm{~kJ} / \mathrm{mol}
$$

$$
\mathrm{CO}+2 \mathrm{H}_{2} \rightleftharpoons \mathrm{CH}_{3} \mathrm{OH} \quad \Delta H^{0}=-91.0 \mathrm{~kJ} / \mathrm{mol}
$$

$$
\mathrm{CO}+\mathrm{H}_{2} \mathrm{O} \rightleftharpoons \mathrm{CO}_{2}+\mathrm{H}_{2} \quad \Delta H^{0}=41.2 \mathrm{~kJ} / \mathrm{mol}
$$

47 The exothermic reactions (1) and (2) represent, respectively, the hydrogenation of $\mathrm{CO}_{2}$ and $\mathrm{CO}$ to methanol. 48 Reaction (3), the water-gas shift (WGS) reaction, is relevant to methanol synthesis as the reaction is also activated 49 by the copper-based methanol synthesis catalysts [8]. As methanol synthesis is exothermic and results in a 50 reduction of molar volume, methanol synthesis is favored by low temperatures and high pressures. However, 
51 temperatures above $200^{\circ} \mathrm{C}$ are required for sufficiently high reaction rates, and thus the thermodynamic equilibrium

52 limits the methanol synthesis to low conversion levels. Hydrogenation of pure $\mathrm{CO}_{2}$ to methanol is also possible but

53 the equilibrium conversions are even lower than for $\mathrm{CO}$. Figure 1 shows the calculated equilibrium conversion of 54 stoichiometric $\mathrm{CO}$ and $\mathrm{CO}_{2}$ feeds at different temperatures and pressure. The conversions are modelled by Soave-

55 Redlich-Kwong equations of state, which have been shown to accurately predict experimental results in methanol 56 synthesis [9]. However, the hydrogenation of $\mathrm{CO}_{2}$ on $\mathrm{Cu} / \mathrm{ZnO}$ catalysts is highly selective to methanol, with other 57 thermodynamically more favorable products such as methane, ethers and ketones formed only in negligible 58 amounts [10].

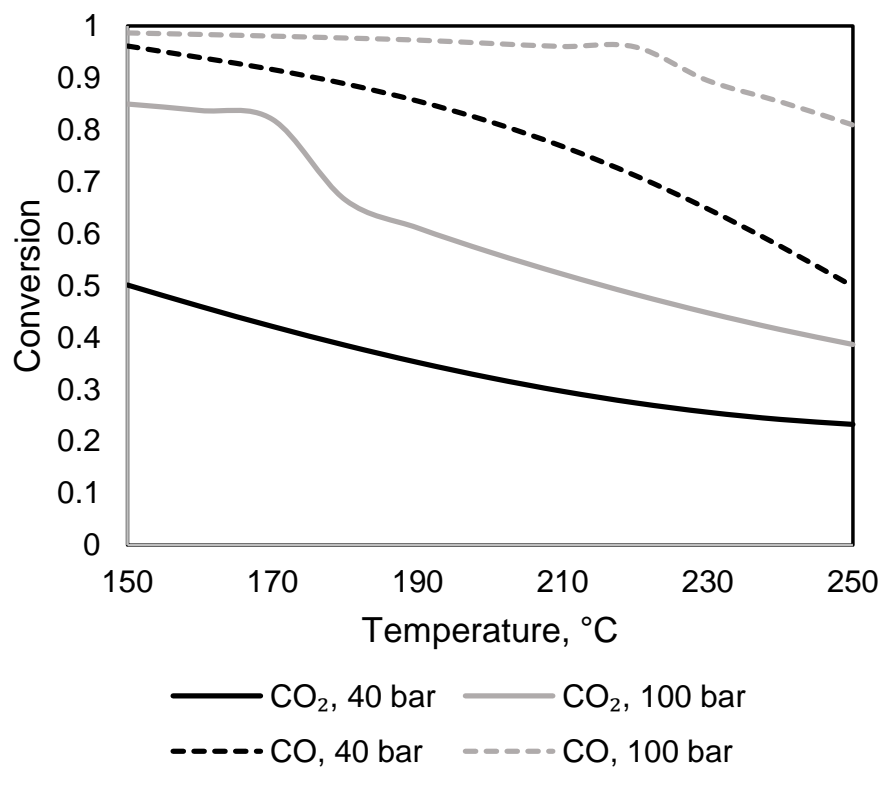

60 Figure 1. Effect of temperature and pressure on the equilibrium carbon conversion from stoichiometric $\mathrm{CO}_{2}: \mathrm{H}_{2}(1: 3)$ and $\mathrm{CO}: \mathrm{H}_{2}(1: 2)$ mixtures. Calculated with the predictive Soave-Redlich-Kwong (PSRK) [11] equation of state in Aspen Plus.

63 To overcome the thermodynamic limitations in the gas-phase methanol process, liquid-phase synthesis processes

64 have been proposed as an alternative approach to enable lower reaction temperatures in syngas reactions. Early 65 developments utilized highly basic catalyst systems such as alkali alkoxides in combination with copper chromite $66[12,13,14]$ or nickel-based catalysts $[15,16,17]$. Methanol synthesis from $\mathrm{CO} / \mathrm{H}_{2}$ at temperatures as low as 100 $67{ }^{\circ} \mathrm{C}$ and pressures between 30 and 65 bar were reported [18]. However, the basic catalysts are incompatible with 
$68 \mathrm{CO}_{2}$ or water, the presence of which, even at trace amounts, leads to rapid catalyst deactivation [17]. A method 69 proposed by the Brookhaven National Laboratory (BNL) also utilized a highly basic system for the conversion of $70 \mathrm{CO}$ to methanol at significantly low temperature and pressure [19]. Furthermore, liquid-phase methanol synthesis 71 from $\mathrm{CO}_{2}$-containing synthesis gas in inert hydrocarbon solvent has been demonstrated in the LPMeOH process $72[20]$.

$73 \mathrm{CO}_{2}$ has been identified as the main carbon source in methanol synthesis from syngas [21]. Hence, it may be 74 expected that methanol can also be produced by hydrogenation of pure $\mathrm{CO}_{2}$. Hydrogenation of $\mathrm{CO}_{2}$, captured from point sources or even directly from the atmosphere, would then provide a sustainable source of carbon-based fuels and chemicals while helping to reduce the atmospheric concentration of $\mathrm{CO}_{2}$ [22]. Some pilot-scale methanol processes that can use $\mathrm{CO}_{2}$ as the starting material have been developed. These include the CAMERE process [23], which combines the reverse water-gas-shift reaction and methanol synthesis from syngas, and the Matsui Chemicals process [24], which directly converts $\mathrm{CO}_{2}$ to methanol. Additionally, Carbon Recycling International established commercial methanol production from $\mathrm{CO}_{2}$ in 2011, and the Svartsengi plant is presently operating at a capacity of above 5 million liters per year [25]. The process utilizes geothermal energy readily available in Iceland.

One possible way to influence the reaction kinetics and conditions is to change the reaction route that leads to the 83 formation of methanol. A novel alcohol-promoted liquid-phase methanol synthesis process first proposed by Fan et 84 al. [26] is based on the combination of a conventional $\mathrm{Cu} / \mathrm{ZnO}$ catalyst and alcohol as a catalytic solvent. The alcohol promotes methanol synthesis by altering the reaction route, allowing operation at lower temperatures. In the presence of the alcohol, the reaction proceeds through the formate ester of the corresponding alcohol as an intermediate. As a result, methanol can be produced from syngas at temperatures starting from $170{ }^{\circ} \mathrm{C}$ and pressures in the range of 30 to 50 bar [27]. Importantly, the process does not employ basic catalysts sensitive to 89 deactivation by $\mathrm{CO}_{2}$, allowing direct conversion of $\mathrm{CO}_{2}$. The following reaction steps have been proposed for this process [28], supported by subsequent in-situ IR observations [29]:

$$
\mathrm{CO}_{2}+\mathrm{H}_{2} \rightleftarrows \mathrm{HCOOH}
$$


2. Reaction of formic acid with ethanol, forming ethyl formate

$$
\mathrm{HCOOH}+\mathrm{C}_{2} \mathrm{H}_{5} \mathrm{OH} \rightleftarrows \mathrm{HCOOC}_{2} \mathrm{H}_{5}+\mathrm{H}_{2} \mathrm{O}
$$

The net reaction is the hydrogenation of carbon dioxide to methanol (Eq. 1) with a standard reaction enthalpy of $49.8 \mathrm{~kJ} / \mathrm{mol}$. Different alcohols have been shown to possess different promoting effect for methanol synthesis. Tsubaki et al. [30] found linear alcohols to be more effective compared to their branched counterparts, with nbutanol showing the best results. Zeng et al. [31] reported that the yield of both methanol and the corresponding ester decreased with increasing carbon number of the 1-alcohols from ethanol to 1-hexanol. For alcohols with the same carbon number but different structure, 2-alcohols were found to have higher activity, which was explained by 106 a combination of spatial and electronic effects. As a result, 2-propanol showed the highest promotional effect. Later, 2-butanol was reported as the most effective solvent for the continuous methanol synthesis in a semibatch reactor [32].

As the alcohol-promoted methanol synthesis process is characterized by two separate reaction steps, the utilization of separate catalysts optimized for each reaction could be beneficial. Such dual- or cascade catalytic systems have been considered previously for methanol synthesis. Huff and Sanford [33] reported effective $\mathrm{CO}_{2}$ conversion to methanol at $135{ }^{\circ} \mathrm{C}$ using a combination of homogeneous catalysts. Chen et al. [34] used heterogeneous catalysts in 1,4-dioxane solvent: copper chromite for the hydrogenation of $\mathrm{CO}_{2}$ to formate and $\mathrm{Cu} / \mathrm{Mo}_{2} \mathrm{C}$ for the formate hydrogenolysis to methanol. This system was capable of methanol production at rates comparable to conventional gas-phase synthesis at $135{ }^{\circ} \mathrm{C}$ and exhibited methanol selectivity above $75 \%$. The methanol synthesis was promoted by the addition of ethanol, with the reaction proceeding through ethyl formate, as reported in the alcoholpromoted process. On the other hand, copper chromite is known to catalyze the hydrogenolysis of esters to alcohols, i.e. the latter stage in the alcohol-promoted reaction route [35]. As such, copper chromite appears an interesting component of a dual catalytic system for alcohol-promoted methanol synthesis. 
120 In comparison to CO-containing syngas feed, $\mathrm{CO}_{2}$ hydrogenation to methanol is further complicated by the 121 increased formation rate of water. Water is formed as a byproduct in methanol synthesis, and in the absence of $122 \mathrm{CO}$, the water-gas shift reaction proceeds in the reverse direction, producing more water. The negative effect of 123 water on methanol synthesis on $\mathrm{Cu} / \mathrm{ZnO}$-based catalysts has been well documented [36]. This effect has been 124 explained as a combination of kinetic inhibition effects and structural catalyst deactivation. Water-derived hydroxyl 125 species can block the active sites on the catalyst, resulting in kinetic inhibition. The presence of water can also 126 accelerate the sintering of copper particles [37], resulting in decreased copper dispersion and catalyst deactivation. 127 Removal of methanol and water using membrane reactors [38, 39] and by condensation at high pressures [40] or 128 low temperatures [41] has been previously described for gas-phase methanol synthesis. Reactive distillation [42] 129 provides a further possible approach for continuous product removal, particularly in liquid-phase processes, and 130 has been proposed in literature for the methanol synthesis process [43] and for the Fischer-Tropsch process [44] 131 operating at similar conditions. In addition, selective removal of water by adsorption on zeolite molecular sieves has 132 also been suggested in sorption-enhanced methanol [45] and related dimethyl ether [46] synthesis operated in the 133 gas-phase.

134 In the present work, alcohol-promoted methanol synthesis was investigated experimentally using a commercial $135 \mathrm{Cu} / \mathrm{ZnO}$-based methanol synthesis catalyst with 1-butanol and 2-butanol as the solvents. 2-butanol was selected 136 because of the previously reported high activity for methanol synthesis, and 1-butanol was considered interesting 137 because of the potentially simplified product separation due to the higher boiling point of the alcohol. As novel 138 developments, enhancement of the alcohol-promoted methanol synthesis by in-situ adsorption of water and by the 139 use of dual catalysts were studied. Water adsorption was carried out using a molecular sieve. Methanol synthesis 140 combined with water removal has previously been modelled based on $4 \AA$ molecular sieves [45], and the use of $4 \AA$ 141 molecular sieves has been modelled for a related dimethyl ether (DME) synthesis [46]. However, experimental work 142 of methanol synthesis promoted by water adsorption has not been published earlier to our knowledge. A dual 143 catalyst system comprising of a combination of $\mathrm{Cu} / \mathrm{ZnO}$ and copper chromite catalysts was tested with the aim of 144 improving methanol productivity by influencing separately the formate formation and hydrogenolysis reaction steps. 


\section{2. Materials and methods}

146 A Parr 4520 autoclave reactor with an inner volume of $450 \mathrm{ml}$ was used for the reaction experiments. The reactor 147 was connected to a Parr 4848 control unit used to control the reaction temperature and mixing speed. A mixing 148 speed of $600 \mathrm{rpm}$ was used in all experiments. Liquid samples from the reaction mixture were collected using a 149 water-cooled sample collection vessel, in which any vapors present in the sample were condensed prior to collecting 150 the sample.

151 Analysis grade 1-butanol and 2-butanol, were used as solvents. A commercial $\mathrm{Cu} / \mathrm{ZnO}$-based methanol synthesis 152 catalyst (Alfa Aesar, $65.5 \% \mathrm{CuO}, 24.7 \% \mathrm{ZnO}, 10.1 \% \mathrm{Al}_{2} \mathrm{O}_{3}, 1.3 \% \mathrm{MgO}$ ) was used. The catalyst was ground and 153 sieved to $150-500 \mu \mathrm{m}$ for each experiment. The $3 \AA$ molecular sieve (UOP, beads with diameter of $2 \mathrm{~mm}$ ), was also 154 ground and sieved to $150-500 \mu \mathrm{m}$. An initial experiment with the unground molecular sieve was also performed. 155 The molecular sieve was activated by heating to $250^{\circ} \mathrm{C}$ for at least 8 hours under air and subsequent cooling to 156 ambient temperature inside a desiccator prior to use. Powdered copper chromite (Sigma-Aldrich) was used in the 157 dual catalyst experiments. A mixed gas containing $75 \%$ hydrogen and $25 \%$ carbon dioxide was used as the reaction 158 feed gas, and a mixed gas containing $5 \%$ hydrogen in nitrogen was used for activation of the catalysts. A diagram 159 of the experimental setup is presented in Figure 2. 


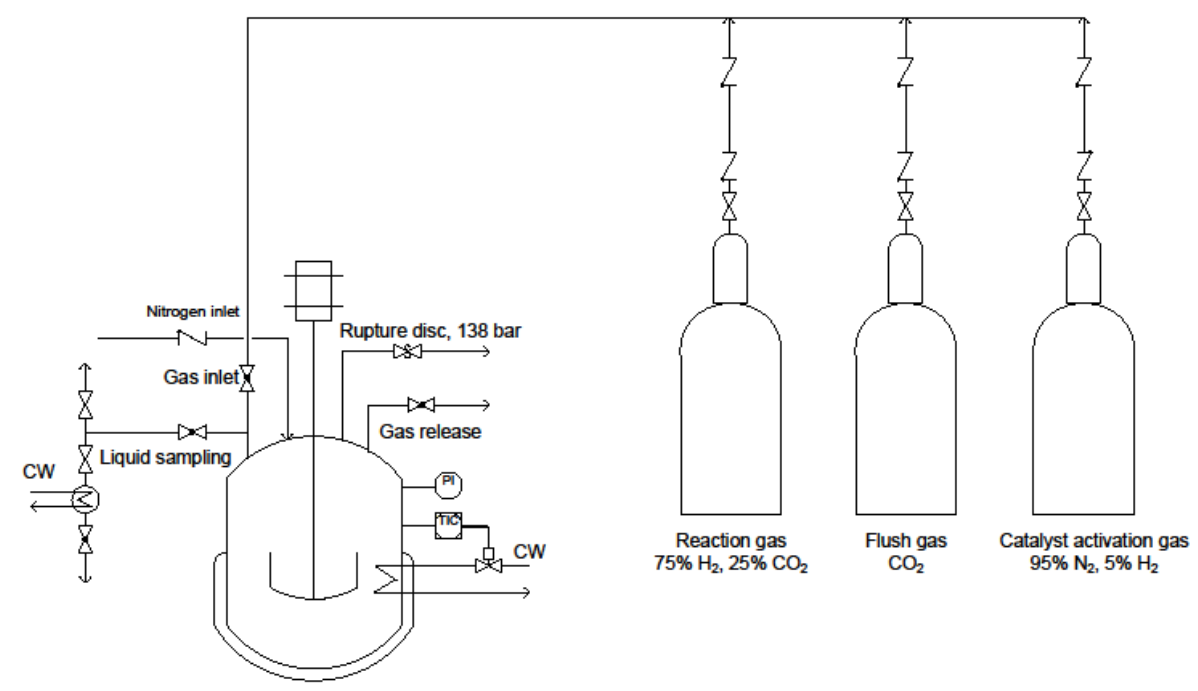

Figure 2. Experimental setup used in the reaction experiments.

162 The ground $\mathrm{Cu} / \mathrm{ZnO}$ catalyst and the copper chromite catalyst were activated in-situ in the reactor vessel. Catalyst 163 activation was performed under 5 bar of the $5 \% \mathrm{H}_{2} / \mathrm{N}_{2}$ mixed gas, with the gas inside the reactor replaced every 30 164 minutes. The temperature was $200{ }^{\circ} \mathrm{C}$ during the activation. Following catalyst activation, the reactor was cooled 165 and the catalysts were kept under the activation gas until the reaction experiment was executed. $200 \mathrm{ml}$ of the 166 alcohol was quickly poured into the reactor, minimizing the contact time of the catalysts with air. The reactor was 167 purged with nitrogen and heated to the reaction temperature under $\mathrm{N}_{2}$. At the reaction temperature, an initial liquid 168 sample was collected and the reactor was pressurized with the feed gas $\left(\mathrm{CO}_{2}: \mathrm{H}_{2}=1: 3\right)$ to the set reaction pressure, 169 which was 60 bar unless otherwise noted. Constant pressure was maintained during the experiments by replacing 170 the consumed reaction gas with fresh gas. The total reaction time was 6 hours and liquid samples were collected 171 every 2 hours.

172 An Agilent Technologies 6890N gas chromatograph with a thermal conductivity detector was used for analysis of 173 the liquid samples. A polar Zebron ZB-WAXplus column was used for the 2-butanol samples. An isothermal method 174 with the column temperature at $70^{\circ} \mathrm{C}$ and helium $(1.1 \mathrm{ml} / \mathrm{min})$ as a carrier gas was used. For the 1 -butanol samples, 175 a non-polar HP-1ms column was used due to insufficient separation of butanal and methanol in the ZB-WAXplus 
176 column. A temperature program with an initial temperature of $50{ }^{\circ} \mathrm{C}$ ( 3 minute hold) followed by a $25^{\circ} \mathrm{C} / \mathrm{min} \mathrm{ramp}$

177 to $100^{\circ} \mathrm{C}$ (3 minute hold) was used. Helium $(0.7 \mathrm{ml} / \mathrm{min})$ was used as the carrier gas. In the ZB-WAXplus column, 178 the retention times were $2.9 \mathrm{~min}$ for methanol, $3.0 \mathrm{~min}$ for 2-butanone, $3.8 \mathrm{~min}$ for 2-butanol, and 3.9 min for water. 179 In the HP-1ms column, the retention times were $2.7 \mathrm{~min}$ for water, $2.9 \mathrm{~min}$ for methanol, $4.7 \mathrm{~min}$ for butanal, and $1805.8 \mathrm{~min}$ for 1 -butanol. Sample concentrations were calculated by the external standard method.

181 Analysis uncertainty was estimated by repeated measurements and by estimation of the uncertainty related to the 182 preparation and analysis of the calibration standards. The total uncertainty is expressed as the relative standard 183 deviation for each product compound in 1-butanol and 2-butanol, which is presented as error bars in the relevant 184 figures. In 1-butanol, the relative standard uncertainty is $8 \%$ for methanol, $11 \%$ for water and $12 \%$ for butanal. In 185 2-butanol, the relative standard uncertainty is $8 \%$ for methanol and $11 \%$ for water. The uncertainty related to the 186 experimental procedure was estimated as relatively insignificant.

187 Characterization of the $\mathrm{Cu} / \mathrm{ZnO}$ catalyst by XRD and SEM-EDS was performed in order to observe any structural 188 changes in the catalyst during the reaction. The catalyst used in methanol synthesis in 1 -butanol at $180{ }^{\circ} \mathrm{C}$ was 189 analyzed before the reaction (in calcined form) following grinding, and also after the experiment. A separate batch 190 of ground catalyst was characterized by XRD following reduction by the method described above.

191 XRD analysis was performed on a Bruker D8 Advance system with Cu-Ka radiation at $2 \theta$ of $20^{\circ}$ to $90^{\circ}$ at $0.02^{\circ}$ 192 increment, with fixed sample illumination and LYNXEYE 1D detector. For analysis, a layer of the ground catalyst in 193 the 150-500 $\mu \mathrm{m}$ particle size range was placed on the plastic powder specimen holder, which was rotated at 10 194 rpm during analysis. Phase analysis was performed in DIFFRAC.SUITE EVA software based on the PDF 4+ 2018 195 database. SEM micrographs and EDS element analyses were obtained using a Hitachi SU3500 Scanning Electron 196 Microscope with SE detector and Thermo Fisher Scientific UltraDry SDD EDS. The acceleration voltage was varied 197 between 10 and $20 \mathrm{kV}$. The samples were introduced as $150-500 \mu \mathrm{m}$ particles on a two-sided carbon tape, without 198 coating.

\section{Results and discussion}

\subsection{Detected reaction products}


201 In addition to methanol and water, significant quantities of alcohol dehydrogenation products were found in the 202 reaction mixture. Alcohol dehydrogenation is known to be catalyzed by copper catalysts [47] with the reaction 203 yielding corresponding aldehydes or ketones and hydrogen as products [48]. For instance, the dehydrogenation of 204 1-butanol yields butanal, while 2-butanol is dehydrogenated to 2-butanone. These reactions have also been 205 identified in other published studies on alcohol-promoted methanol synthesis [49].

206 Figure 3 depicts a typical concentration profile of the observed reaction products in 1-butanol during 6 hours of 207 reaction time. The temperature was $180^{\circ} \mathrm{C}$ and pressure 60 bar for the experiment depicted. Similar concentration 208 curves were observed for all reaction conditions and alcohols used.

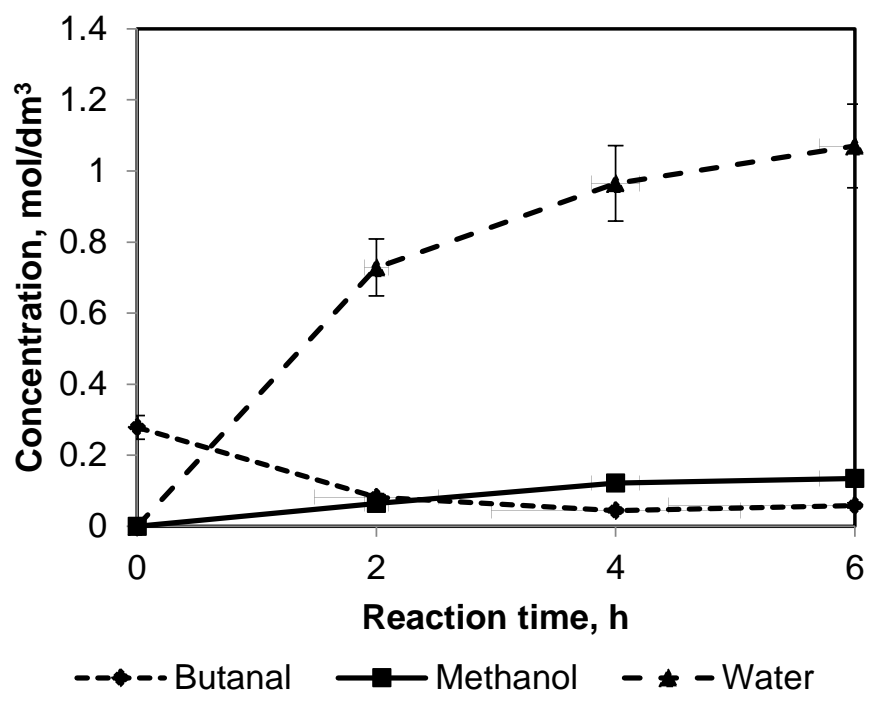

Figure 3. Typical concentration profile of the detected reaction products in 1-butanol. $20 \mathrm{~g}$ of $\mathrm{Cu} / \mathrm{ZnO}$ catalyst in $200 \mathrm{ml}$ of alcohol, temperature $180^{\circ} \mathrm{C}$, feed gas $\mathrm{CO}_{2}: \mathrm{H}_{2}=1: 3$, total pressure 60 bar.

212 The highest concentration of dehydrogenation products was found after heating of the reaction mixture prior to 213 introducing the reaction feed gas. A corresponding increase in the reactor pressure was noticed during the heating 214 process. The pressure increase was presumably caused by the hydrogen formed in the alcohol dehydrogenation 215 reaction. The peak concentration of the dehydrogenation products varied depending on the temperature and the 216 alcohol used but always remained below $10 \%$ of the total solution on a mass fraction basis. However, the 217 concentration of the aldehyde or ketone significantly decreased under the reaction gas atmosphere with increasing 218 reaction time. The dehydrogenation reactions appear to reverse direction under increased hydrogen pressure, 
219 returning the original alcohols to the solution. Due to the relatively minor conversion of the alcohols and the apparent 220 reversibility of these reactions, alcohol dehydrogenation is not considered harmful for the overall process.

221 The concentration of methanol continuously increases over the 6 hours of reaction time. Thus, equilibrium 222 conversion is not reached during this time, and more methanol would likely form if the reaction time were increased. 223 The higher total concentrations of methanol and water found in the molecular sieve experiments (Section 3.3 Water 224 removal by molecular sieveare further evidence that the equilibrium product concentration is not reached. However, 225 in many of the experiments, the methanol production rate decreases after 4 hours of reaction time, as evidenced 226 by the declining slope of the methanol concentration curve in Figure 3. As the thermodynamic equilibrium is not 227 reached at this point, the methanol synthesis rate appears to be limited by kinetic effects, most likely by inhibition 228 caused by the by-product water.

229 The concentration of water also increases during the reaction as water is formed both as the by-product of $\mathrm{CO}_{2}$ 230 hydrogenation to methanol and also in the RWGS reaction. The amount of water formed is significantly higher than 231 the amount of methanol. In 1 -butanol at $180{ }^{\circ} \mathrm{C}$, the end concentration of water is almost 7 times the end 232 concentration of methanol (Figure 3). A similar result is found at higher reaction temperatures. Figure 4 presents 233 the concentrations of methanol and water in 1-butanol at reaction temperatures of 180,200 and $220{ }^{\circ} \mathrm{C}$.

234 If water is only formed as the by-product of methanol synthesis, the molar amounts of methanol and water formed 235 should be equal. The much higher concentrations of water compared to methanol suggest that a significant majority 236 of the water is formed in reactions other than methanol synthesis. On the $\mathrm{Cu} / \mathrm{ZnO}$ catalyst, the RWGS reaction is 237 most likely the source of the excess water. The high molar ratios of water to methanol formed would suggest that 238 the RWGS reaction is the main reaction in this system and the total selectivity to methanol is rather low. In 1-butanol 239 (Figure 4), the molar ratio of water to methanol ranges approximately from 7 to 10 , which implies methanol selectivity 240 in the range of $10-20 \%$. Some water is also present at the start of the reaction, most likely formed during the 241 reduction of the catalyst. This amount of water is significant in some of the experiments, for example, in 1-butanol 242 at $220^{\circ} \mathrm{C}$ (Figure 4), constituting a potential disadvantage of the in-situ catalyst activation method.

243 Although hydrogenation of the esters is considered to be the rate-determining step in this process [26], 244 alkyl formates, the intermediate products of alcohol-promoted methanol synthesis, were not detected in 
245 the reaction mixture, neither in 1-butanol nor in 2-butanol. The formate esters appear to be rapidly 246 hydrogenated into methanol and alcohol (reaction 9) and their concentrations remain below the detection 247 limit of the analysis method. As the intermediates were not detected, it was not possible to confirm that 248 the reactions proceed through the suggested reaction route. However, the overall promoting effect of the 249 alcohols was convincingly confirmed by a blank experiment in hexane at $180^{\circ} \mathrm{C}$, in which no methanol 250 was formed.

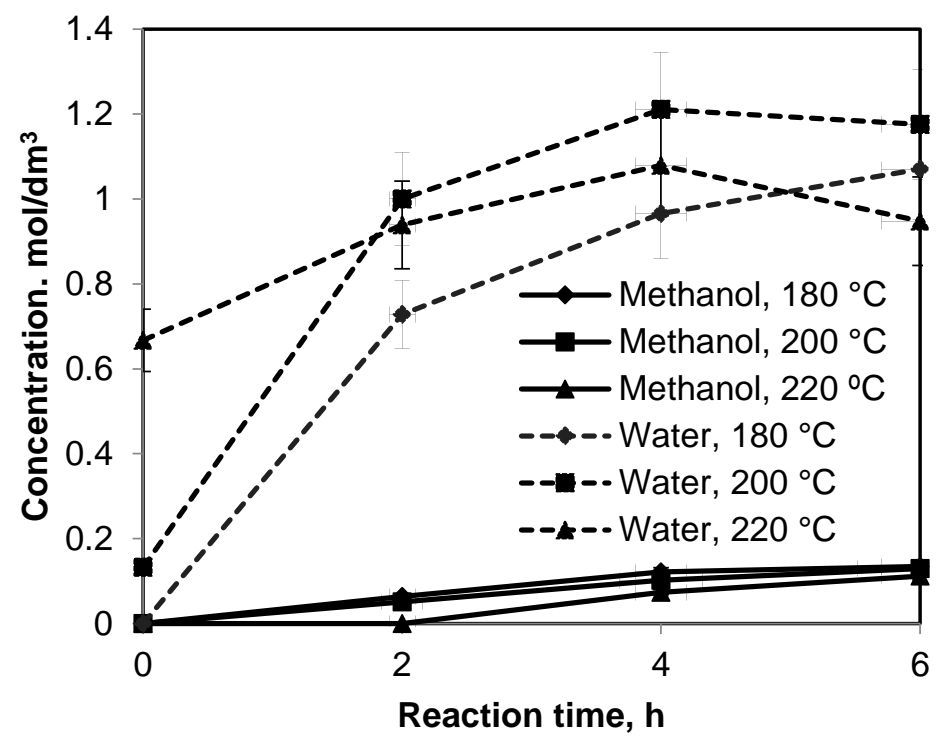

251

Figure 4. Overall effect of temperature on the formation of methanol and water in alcohol promoted methanol synthesis with 1-butanol as solvent. $20 \mathrm{~g}$ of $\mathrm{Cu} / \mathrm{ZnO}$ catalyst. Feed gas $\mathrm{CO}_{2}: \mathrm{H}_{2}=1: 3$. Total pressure 60 bar. Error bars for the concentration of water at 180 and $200{ }^{\circ} \mathrm{C}$ are omitted for clarity.

\subsection{Effect of reaction temperature and pressure}

Reactions in 1-butanol were carried out using a constant overall pressure at different temperatures. Figure 5 shows the combined effect of the reaction temperature and the partial pressure of the reaction gas on methanol productivity with constant total pressure at 180,200 and $220^{\circ} \mathrm{C}$. The methanol productivity is measured as grams of methanol produced per kg of catalyst per hour. The concentrations of the reaction products in these experiments are shown in Figure 4. Methanol productivity is found to decrease with increasing temperature at the temperature range studied. This result can be explained by the decreased partial pressure of the reaction gas due to increased vapor 
pressure of 1-butanol at constant total pressure. The partial pressures, shown also in Figure 5, are calculated by 263 subtracting the alcohol vapor pressure from the total reaction pressure.
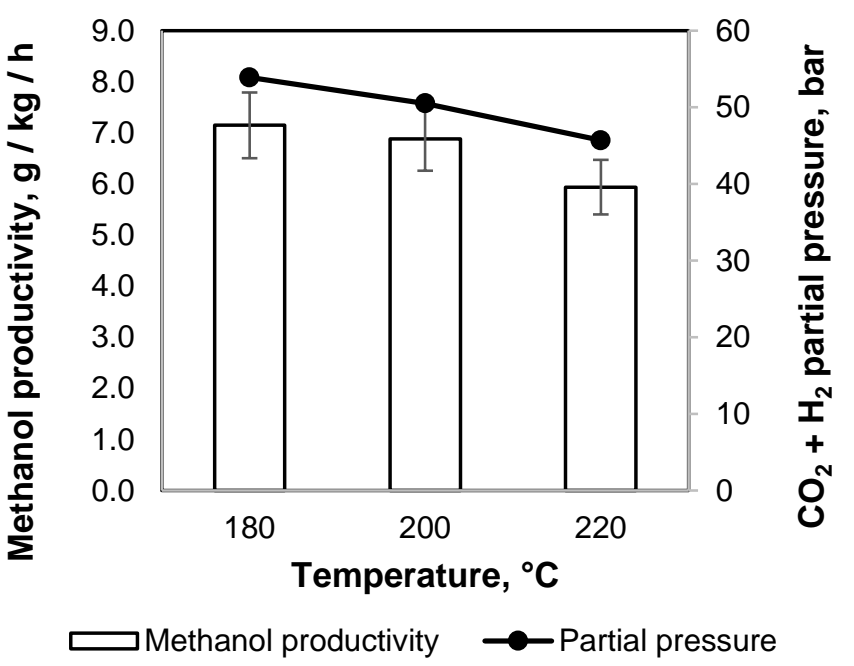

265 Figure 5. Effect of temperature on methanol productivity with $20 \mathrm{~g}$ of $\mathrm{Cu} / \mathrm{ZnO}$ catalyst in $200 \mathrm{ml}$ of 1-butanol. Reaction time 6 hours, feed gas $\mathrm{CO}_{2}: \mathrm{H}_{2}=1: 3$, total pressure 60 bar.

267 As the concentration of water did not markedly change when the reaction temperature was varied (Figure 4), it can 268 be concluded that the effect of the RWGS reaction does not explain the lowered methanol productivity at increased 269 temperature.

270 In theory, the reduced methanol synthesis rate at increased temperatures could also be explained by increased 271 selectivity to $\mathrm{CO}$. Increased CO formation by the RWGS reaction should also lead to increased production of water, 272 as water is also formed in the RWGS reaction. The increased concentrations of water would further inhibit the rate 273 of methanol synthesis. However, the concentration of water did not markedly change when the reaction temperature 274 was varied (Figure 4). Thus, it is concluded that the RWGS reaction does not explain the lowered methanol 275 productivity at increased temperature.

276 The reactions in 2-butanol were carried out using a constant reaction gas partial pressure at different temperatures 277 and a constant temperature at different reaction gas partial pressures. The effect of the feed gas partial pressure 278 on methanol productivity can be clearly seen in Figure 6, which presents methanol productivity at different reaction 
279 temperatures with $\mathrm{CO}_{2}+\mathrm{H}_{2}$ partial pressure fixed to 40 bar by varying the total reaction pressure. A significant 280 increase in the methanol production rate with increasing reaction temperature is observed.

281 Figure 7 presents the methanol productivity at a fixed reaction temperature of $180^{\circ} \mathrm{C}$ with the feed gas partial 282 pressure varied from 30 to 50 bar. The productivity clearly increases with the increased partial pressure. The 283 obtained productivities in 2-butanol seem to be higher than in 1-butanol. It should however be noted that the higher 284 productivity values in 2-butanol might be explained by the lower amount $(10 \mathrm{~g})$ of catalyst used. The specific 285 productivity of the catalyst appears to decrease as a result of increased water formation due to the RWGS reaction 286 when larger amounts of catalysts are used. This effect is discussed further in Section 3.3.

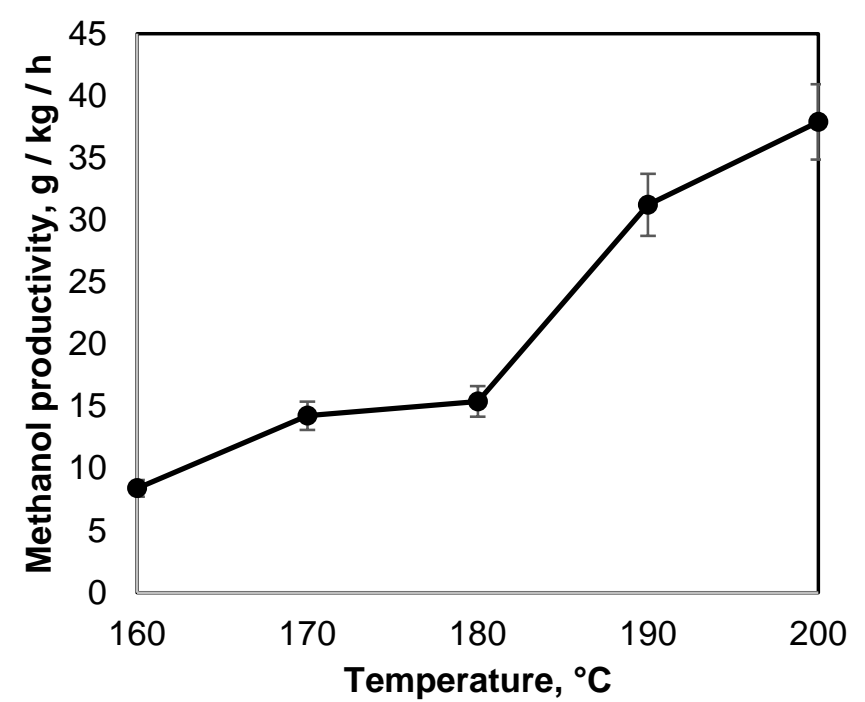

288 Figure 6. Effect of temperature on methanol productivity with $10 \mathrm{~g}$ of $\mathrm{Cu} / \mathrm{ZnO}$ catalyst in $200 \mathrm{ml}$ of 2butanol. Feed gas $\left(\mathrm{CO}_{2}: \mathrm{H}_{2}=1: 3\right)$, partial pressure 40 bar, reaction time $6 \mathrm{~h}$. 


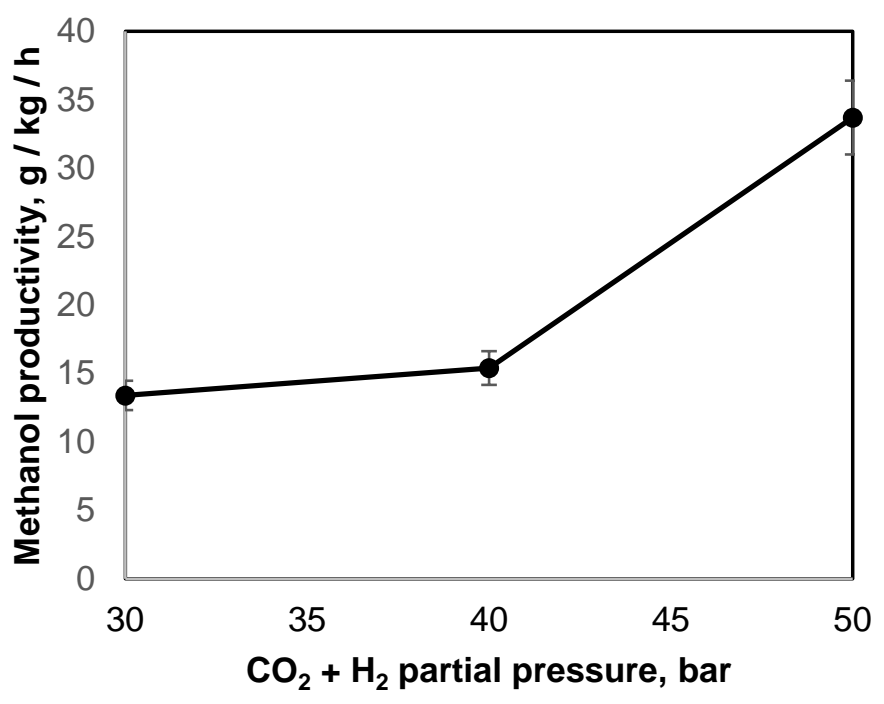

Figure 7. Effect of reaction gas partial pressure on methanol productivity with $10 \mathrm{~g}$ of $\mathrm{Cu} / \mathrm{ZnO}$ catalyst in 2butanol at $180{ }^{\circ} \mathrm{C}$. Feed gas $\left(\mathrm{CO}_{2}: \mathrm{H}_{2}=1: 3\right)$, reaction time $6 \mathrm{~h}$.

\subsection{Water removal by molecular sieve}

294 Continuous removal of water from the reaction mixture was tested by addition of a zeolite molecular sieve. Molecular 295 sieves with a pore diameter of $3 \AA$ can be used for the dehydration of alcohols because of their selective adsorption 296 of water [50]. The selective adsorption is based on size exclusion of molecules larger than water in the inner 297 microporous structure of the zeolite.

298 The limiting effect of water on the alcohol-promoted methanol synthesis process was first confirmed by performing 299 an experiment with approximately $1.4 \mathrm{~mol} / \mathrm{dm}^{3}$ of water added to 2-butanol. This concentration is slightly above the 300 maximum concentration range of water found in the experiments (Figure 4). At $180^{\circ} \mathrm{C}$ and 60 bar of total pressure, 301 the methanol production rate was approximately $74 \%$ lower than in the base experiment with no water added. The 302 concentration of water did not significantly increase during this experiment but rather remained relatively constant 303 at the apparent equilibrium level.

304 Next, the effect of in-situ adsorption of water by the addition of a $3 \AA$ molecular sieve was tested. The relative 305 amounts of the catalyst and the molecular sieve were varied, maintaining a total solids mass of $50 \mathrm{~g}$. The results of 306 these experiments are presented in Figure 8. A base experiment with $20 \mathrm{~g}$ of catalyst and no molecular sieve is 307 also presented for comparison. 




Figure 8. Effect of catalyst and molecular sieve mass on methanol and water formation in 2-butanol. Temperature $180^{\circ} \mathrm{C}$, feed gas $\mathrm{CO}_{2}: \mathrm{H}_{2}=1: 3$, total pressure 60 bar.

311 Compared to the base case with $20 \mathrm{~g}$ of $\mathrm{Cu} / \mathrm{ZnO}$ catalyst and no molecular sieve, the addition of the unground 312 molecular sieve increased the methanol productivity from $8.2 \mathrm{~g} / \mathrm{kg} / \mathrm{h}$ to $11.2 \mathrm{~g} / \mathrm{kg} / \mathrm{h}$. A more significant improvement 313 was found with the molecular sieve ground into 150-300 $\mu \mathrm{m}$ particle size range. Due to the clear effect of the particle 314 size, the adsorption of water appears to be significantly diffusion-limited for the unground molecular sieve. With 20 $315 \mathrm{~g}$ of catalyst, the addition of $30 \mathrm{~g}$ of the ground molecular sieve increases the methanol productivity to $33.6 \mathrm{~g} / \mathrm{kg} / \mathrm{h}$, 316 an increase of over $300 \%$ over the $\mathrm{Cu} / \mathrm{ZnO}$ catalyst used without a molecular sieve. Keeping the total amount of 317 solids (catalyst + molecular sieve) at $50 \mathrm{~g}$, the methanol productivity increased with increasing amounts of molecular 318 sieve. For instance, the productivity increased to $54.4 \mathrm{~g} / \mathrm{kg} / \mathrm{h}$ using $10 \mathrm{~g}$ of the catalyst and $40 \mathrm{~g}$ of the molecular 319 sieve. These results clearly show that the catalyst is most effectively utilized for methanol synthesis when larger 320 relative amounts of the molecular sieve to the catalyst are used. This observation can be explained by the increased 321 water adsorption capacity of the larger amount of the molecular sieve, leading to decreased concentrations of water, as shown in Figure 8. 


\subsection{Dual catalysts}

325 To test the dual catalysis concept for alcohol-promoted methanol synthesis, copper chromite (CuCr) was used in 326 combination with the $\mathrm{Cu} / \mathrm{ZnO}$ catalyst. The ratios of the two catalysts were varied: $20 \mathrm{~g}$ of the $\mathrm{Cu} / \mathrm{ZnO}$ catalyst was 327 used with $10 \mathrm{~g}$ of $\mathrm{CuCr}$, and vice versa. The experiments were carried out in 2-butanol at $180{ }^{\circ} \mathrm{C}$ and 60 bar of total pressure, corresponding to a $\mathrm{CO}_{2}+\mathrm{H}_{2}$ partial pressure of 50.1 bar. The results of these experiments are presented

329 in Figure 9. A base experiment with $20 \mathrm{~g}$ of $\mathrm{Cu} / \mathrm{ZnO}$ catalyst and no copper chromite is also presented for 330 comparison.



Figure 9. Effect of different amounts of $\mathrm{Cu} / \mathrm{ZnO}$ and copper chromite $(\mathrm{CuCr})$ catalysts on the formation of methanol and water in 2-butanol. Reaction time 6 hours. Temperature $180^{\circ} \mathrm{C}$, feed gas $\mathrm{CO}_{2}: \mathrm{H}_{2}=$

The addition of the copper chromite catalyst clearly increases the methanol productivity. Both the absolute methanol production rate, as measured by the methanol end concentration, and the specific productivity of the catalyst $1: 3$, total pressure 60 . An experiment with $20 \mathrm{~g}$ of $\mathrm{Cu} / \mathrm{ZnO}$ catalyst and no copper chromite is included for comparison. increase with addition of copper chromite. The increased productivity can be explained either by a synergistic effect between the two catalysts or by higher methanol synthesis activity of $\mathrm{CuCr}$ compared to $\mathrm{Cu} / \mathrm{ZnO}$. However, a higher intrinsic activity of copper chromite appears unlikely, as the activity of $\mathrm{Cu} / \mathrm{ZnO}$ for methanol synthesis is well-known 
341 and industrially applied. Fan et al. [26] also reported higher methanol yield and selectivity of $\mathrm{Cu} / \mathrm{ZnO}$ compared to

$342 \mathrm{CuCr}$ in alcohol promoted methanol synthesis. Fan et al. also found similar CO selectivity, or RWGS activity, for

343 both of the catalysts. This is supported by the present results, as the concentration of water was not significantly 344 affected by the changed ratio of $\mathrm{Cu} / \mathrm{ZnO}$ and $\mathrm{CuCr}$ (Figure 9, columns 2 and 3), supporting similar RWGS activity 345 of the two catalysts. The overall methanol selectivity appears to be higher with the combined catalysts, as the ratio 346 of methanol to water produced is increased compared to $\mathrm{Cu} / \mathrm{ZnO}$ used alone.

\subsection{Characterization of $\mathrm{Cu} / \mathrm{ZnO}$ catalyst before and after reaction}

348 The structural features of the $\mathrm{Cu} / \mathrm{ZnO}$ catalyst before and after reaction were investigated by the means 349 of XRD and SEM-EDS in order to assess the catalyst stability. Figure 10 presents the X-ray 350 diffractograms of the catalyst as supplied in the calcined form, following reduction in $5 \%$ hydrogen, and 351 following use in alcohol-promoted methanol synthesis in 1-butanol at $180^{\circ} \mathrm{C}$. It is noted that the same 352 batch of catalyst was analyzed prior to reduction and following the reaction, while the reduced catalyst 353 was prepared and analyzed separately.

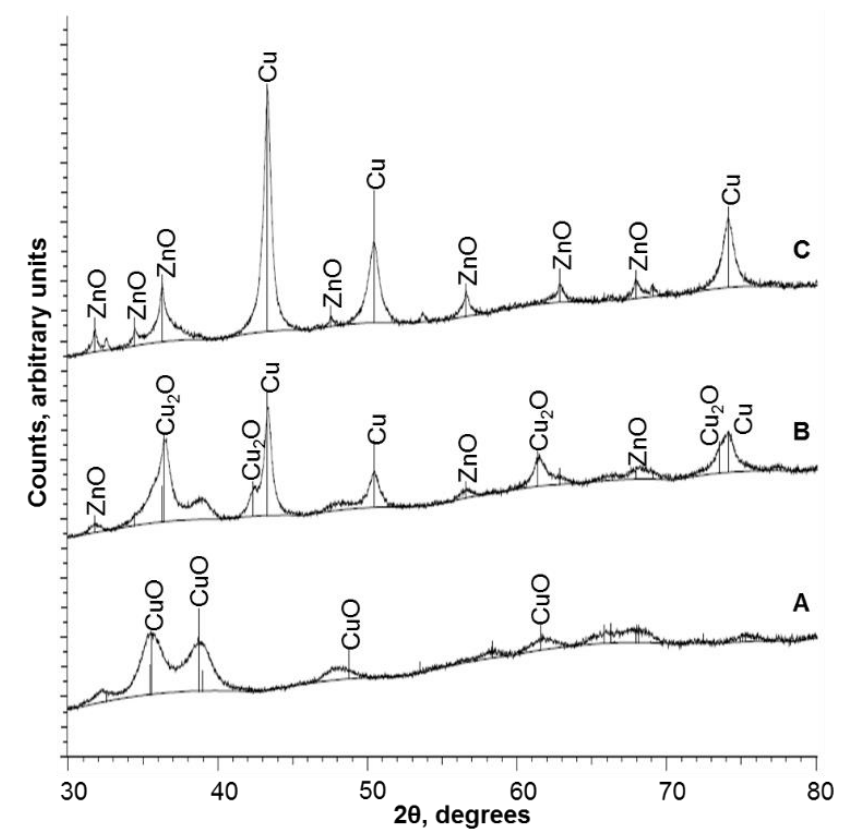

Figure 10. X-ray diffractograms of the unused $\mathrm{Cu} / \mathrm{ZnO}$ catalyst $(\mathrm{A})$, the reduced catalyst $(\mathrm{B})$, and the catalyst following methanol synthesis from $\mathrm{CO}_{2}$ and $\mathrm{H}_{2}(1: 3)$ in 1-butanol at $180{ }^{\circ} \mathrm{C}(\mathrm{C})$. 
357 The calcined catalyst is largely amorphous, showing a minor pattern corresponding to copper(II)oxide

358 (CuO) typical to $\mathrm{Cu} / \mathrm{ZnO}$ catalysts [51]. The patterns are identified based on the PDF 4+ 2018 359 crystallography database. The reduced catalyst presents with a clearly defined pattern consistent with 360 crystalline, copper $(\mathrm{I})$ oxide $\left(\mathrm{Cu}_{2} \mathrm{O}\right)$, and metallic copper. Weak crystalline features of zinc oxide are also 361 evident, consistent with previous studies [52]. As the reduction of copper proceeds stepwise from CuO 362 to $\mathrm{Cu}$ via $\mathrm{Cu}_{2} \mathrm{O}$ [53], the presence of $\mathrm{Cu}_{2} \mathrm{O}$ may imply incomplete reduction, possibly due to insufficient 363 reduction time or temperature. However, as the reduced catalyst sample was transferred and analyzed 364 in contact with air, re-oxidation of copper crystallites during this process cannot be ruled out.

365 Only metallic copper and zinc oxide is found present in the used catalyst. $\mathrm{Cu} / \mathrm{ZnO}$ catalysts are known to 366 show dynamic structural changes depending on the oxidation potential of the gas phase $[54,55]$ and 367 ongoing reduction of the catalyst at the reaction conditions is possible. As the reduced and used catalyst 368 analyzed here are not from the same batch of ground and prepared catalyst, batch-to-batch variation 369 cannot be eliminated as a cause of the observed structural differences.

370 The peaks corresponding to zinc oxide are more clearly defined compared to the reduced catalyst, 371 potentially indicating continuing crystallization of $\mathrm{ZnO}$ at the reaction conditions. Lunkenbein et al. [56] 372 identified zinc oxide as the more dynamic phase compared to metallic copper under reaction conditions, 373 and found that crystallization of $\mathrm{ZnO}$ and the resulting loss of reactive $\mathrm{Cu}-\mathrm{ZnO}$ interfaces is the main 374 mechanism of initial catalyst deactivation. The SEM-EDS elemental maps of copper and zinc presented 375 in Figure 11 indicate that such a process may have initiated in the catalyst used here. The unused 376 (calcined) catalyst shows a relatively homogeneous distribution of both copper and zinc. However, a 377 degree of segregation of these elements can be observed in the used catalyst, with the elemental map 378 showing distinct areas with high content of zinc (oxide) that are relatively poor in copper. 

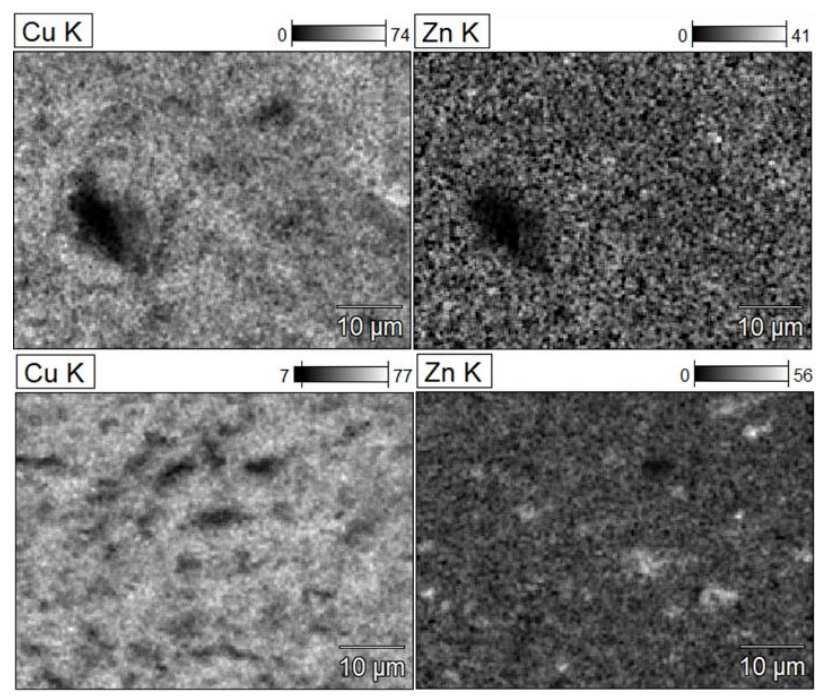

Figure 11. SEM-EDS elemental maps of copper and zinc in the unused $\mathrm{Cu} / \mathrm{ZnO}$ catalyst (upper), and the catalyst following methanol synthesis from $\mathrm{CO}_{2}$ and $\mathrm{H}_{2}$ (1:3) in 1-butanol at 180 ${ }^{\circ} \mathrm{C}$ (lower). Composition scales in weight percent.

384 Further insight is provided by the SEM images presented in Figure 12. Distinct crystals in the 385 micrometer dimension can be observed, identified as zinc oxide by the EDS analysis. No such features 386 were found in the unused catalyst. It is concluded that agglomeration and crystallization of zinc oxide 387 during reaction has occurred, acting as a potential deactivation mechanism for the catalyst. However, 388 as long-term stability tests were not performed here, the actual effect of these structural changes on the 389 activity of the catalyst cannot be discussed.

390 These observations can be compared to other findings discussed in literature. Previously, the stability 391 of $\mathrm{Cu} / \mathrm{ZnO}$ catalyst in alcohol promoted methanol synthesis has been explored by Reubroycharoen et 392 al. [32] who found the performance stable during 40 hours of continuous methanol synthesis (at 170 $393{ }^{\circ} \mathrm{C}$ ), and by Jeong et al. [57] who found no decline in activity during 60 hours of reaction $\left(150^{\circ} \mathrm{C}\right)$. In 394 contrast to our results, Jeong et al. found no changes in the XRD profile of the catalyst before and after 395 reaction. Other than the lower reaction temperature, the differing findings might be explained by 396 different feed gas composition, as a CO-rich syngas was used in these studies opposed to the $\mathrm{CO}_{2}: \mathrm{H}_{2}$ 
mixture used here. Therefore, it is possible that the detected differences might be caused by the large amount of water present in the reaction system in the present study.

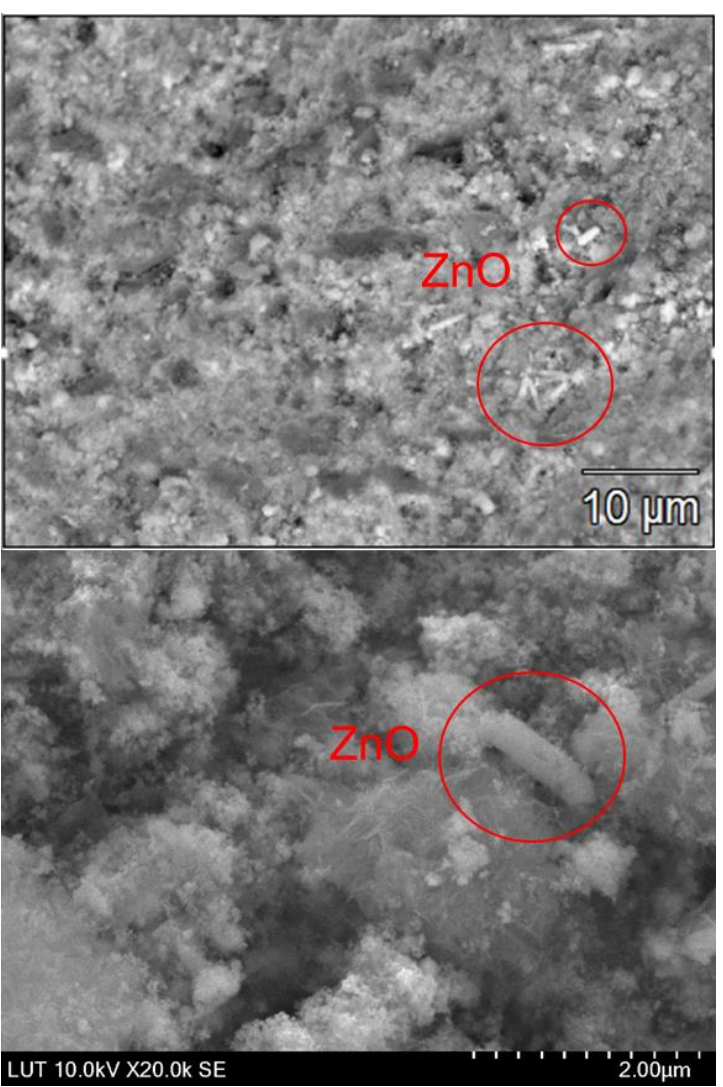

Figure 12. SEM micrographs of the $\mathrm{Cu} / \mathrm{ZnO}$ catalyst following methanol synthesis from $\mathrm{CO}_{2}$ and $\mathrm{H}_{2}$ $(1: 3)$ in 1-butanol at $180^{\circ} \mathrm{C}$. Zinc oxide crystals are highlighted.

\section{Conclusions}

403 Methanol synthesis from $\mathrm{CO}_{2}$ was studied in an alcohol-promoted liquid-phase process using conventional $\mathrm{Cu} / \mathrm{ZnO}$ 404 and copper chromite as catalysts. 1-butanol and 2-butanol were found to act as catalytic solvents, allowing methanol 405 synthesis at lower temperatures than conventional gas-phase processes. Although it was not possible to determine 406 the exact reaction route, it is expected that the promoting effect of the alcohols is based on a reaction route 407 proceeding through the intermediate of formate ester of the alcohol.

408 The effect of continuous water removal using molecular sieve adsorption was explored. The addition of a $3 \AA$ 409 molecular sieve significantly enhanced methanol productivity. Grinding of the molecular sieve resulted in improved 410 results due to the shorter diffusion path compared to the granular material. The maximum methanol productivity of 
$41154.4 \mathrm{~g} / \mathrm{kg} / \mathrm{h}$ was found when the maximum relative amount of the molecular sieve $(40 \mathrm{~g})$ to the catalyst (10 g) was 412 used. The final methanol concentration after 6 hours of reaction time reached $0.5 \mathrm{~mol} / \mathrm{dm}^{3}$. The catalyst was most 413 effectively used for methanol synthesis when the amount of molecular sieve was maximized, which minimized the 414 concentration of water. The water concentration was found to significantly affect the rate of methanol synthesis. 415 The overall methanol production rate in this process appears to be limited by the concentration of water and its 416 effects on the catalyst surface. To prevent the negative effects of water, continuous water removal or development 417 of more water resistant catalysts is vital for further development of this process. Based on the results, the use of a $4183 \AA ̊$ molecular sieve for water removal appears a promising approach.

419 The methanol productivity obtained in the current research can be compared to results reported in other studies. 420 Yang et al. [49] found an even higher methanol productivity of up to $167 \mathrm{~g} / \mathrm{kg} / \mathrm{h}$ for alcohol-promoted methanol 421 synthesis at $170{ }^{\circ} \mathrm{C}$ and 50 bar using an optimized $\mathrm{Cu} / \mathrm{ZnO}$ catalyst composition. The difference to the results 422 presented here can be explained mainly by the different feed gas composition in their experiments $\left(\mathrm{CO} / \mathrm{CO}_{2} / \mathrm{H}_{2} / \mathrm{Ar}\right.$ $423=32.4 / 5 \cdot 1 / 59 \cdot 5 / 3 \cdot 9)$. For gas-phase $\mathrm{CO}_{2}$ hydrogenation to methanol, productivity values even up to $1200 \mathrm{~g} / \mathrm{kg} / \mathrm{h}$ 424 have been achieved [58]. However, these results were obtained at a relatively high temperature of $240{ }^{\circ} \mathrm{C}$ and at 425 high space velocities giving relatively low $\mathrm{CO}_{2}$ conversions.

426 Dual catalysis by the combination of $\mathrm{Cu} / \mathrm{ZnO}$ with copper chromite was also studied in this work. A remarkable 427 increase in catalytic activity was found for the dual catalyst. When $20 \mathrm{~g}$ of copper chromite and $10 \mathrm{~g}$ of $\mathrm{Cu} / \mathrm{ZnO}$ was 428 used, the productivity increased by $80 \%$ compared to the use of $20 \mathrm{~g}$ of the $\mathrm{Cu} / \mathrm{ZnO}$ catalyst alone. A synergistic 429 effect between the two catalysts is suggested, which is possibly based on an increased formation rate of the formate 430 ester intermediate by the copper chromite catalyst. The two catalysts appeared to have similar reverse water-gas 431 shift activity, as the concentration of water did not change when the relative amounts of $\mathrm{Cu} / \mathrm{ZnO}$ and copper chromite 432 were varied.

433 Structural changes in the catalyst during alcohol-promoted methanol synthesis were found by the means of XRD 434 and SEM-EDS investigations. EDS elemental analysis showed that segregation of copper and zinc oxide had taken 435 place, and both XRD analysis and SEM imaging provided evidence that crystallization of zinc oxide occurred. Such 436 phenomena has previously been identified as cause of catalyst deactivation due to the loss of reactive $\mathrm{Cu}-\mathrm{ZnO}$ 437 interfaces [56]. However, comprehensive catalyst stability tests were not performed in the current study, and thus 
438 the effect of the observed changes on catalytic activity cannot be determined conclusively. It is clear that stability 439 tests at different reaction temperatures and, importantly, at different feed gas compositions are necessary to further 440 characterize the alcohol-promoted methanol synthesis process.

\section{Acknowledgements}

442 The Authors are grateful for Finnish Academy of Science for "Micro- and millistructured reactors for catalytic 443 oxidation reactions" MICATOX project funding, number: 269896. Funding provided by the Lappeenranta 444 University of Technology Doctoral School is also gratefully acknowledged. 
[1] R. Schlögl, "The solar refinery," in Chemical Energy Storage, Berlin/Boston, Walter de Gruyter GmbH, 2013, pp. 1-34.

[2] F. Schüth, "Energy storage strategies," in Chemical Enery Storage, Berlin/Boston, Walter de Gruyter $\mathrm{GmbH}, 2013$, pp. 35-48.

[3] G. Olah, "Beyond oil and gas: The methanol economy," Angew. Chem. Int. Ed., vol. 44, pp. 2636-2639, 2005. doi:10.1002/anie.200462121

[4] H. Offermanns, L. Plass and M. Bertau, "From raw materials to methanol, chemicals, and fuels" in Methanol: The Basic Chemical and Energy Feedstock of the Future, Berlin Heidelberg, Springer-Verlag, 2014, pp. 1-7. doi:10.1007/978-3-642-39709-7

[5] L. Reichelt and F. Schmidt, "Methanol-to-gasoline process," in Methanol: The Basic Chemical and Energy Feedstock of the Future, Berlin Heidelberg, Springer-Verlag, 2015, pp. 440-453. doi:10.1007/978-3-642-39709-7

[6] F. Schmidt and C. Pätzold, "Methanol-to-olefins processes," in Methanol: The Basic Chemical and Energy Feedstock of the Future, Berlin Heidelberg, Springer-Verlag, 2015, pp. 454-472. doi:10.1007/978-3-642-39709-7

[7] J. Ott, V. Gronemann, F. Pontzen, E. Fiedler, G. Grossmann, Kersebohm, D.B., G. Weiss and C. Witte, "Methanol," in Ullmann's Encyclopedia of Industrial Chemistry, Weinheim, Wiley-VCH Verlag GmbH \& Co. KGaA, 2012, pp. 1-27. doi:10.1002/14356007

[8] S. Lee, "Methanol synthesis from syngas," in Handbook of Alternative Fuel Technology, Taylor \& Francis Group, LLC, 2007, pp. 297-321.

[9] J. Skrzypek, M. Lachowska, M. Grzesik, J. Sloczynski and P. Nowak, "Thermodynamics and kinetics of low pressure methanol synthesis," Chem. Eng. J., vol. 58, pp. 101-108, 1995. doi:10.1016/0923-0467(94)02955-5

[10] E. Kunkes and M. Behrens, "Introduction to methanol synthesis and steam reforming," in Chemical Energy Storage, Berlin, Walter de Gruyter GmbH, 2013, pp. 415-417.

[11] T. Holderbaum and J. Gmehling, "PSRK: A group contribution equation of state based on UNIFAC," Fluid Phase Equilib., vol. 70, pp. 251-265, 1991. doi:10.1016/0378-3812(91)85038-V

[12] V. Palekar, "Alkali compounds and copper chromite as low-temperature slurry phase methanol catalysts," Appl. Catal., A, vol. 103, no. 1, pp. 105-122, 1993. doi:10.1016/0926860X(93)85177-Q

[13] Y. Zhao, L. Bai, Y. Hu, B. Zhong and S. Peng, "Catalytic performance of $\mathrm{CuCr} / \mathrm{CH}_{3} \mathrm{ONa}$ used for low temperature methanol synthesis in slurry phase," J. Nat. Gas Chem., vol. 8, no. 3, pp. 181-187, 1999.

[14] W. Chu, T. Zhang, C. He and Y. Wu, "Low-temperature methanol synthesis (LTMS) in liquid phase on novel copper-based catalysts," Catal. Lett., vol. 79, pp. 129-132, 2002. doi:10.1023/A:1015384015528

[15] M. Marchionna, L. Basini, A. L. M. Aragno and F. Ancillotti, "Mechanistic studies on the homogeneous nickel-catalyzed low temperature methanol synthesis," J. Mol. Catal., vol. 75, no. 2, pp. 147-151, 1992. doi:10.1016/0304-5102(92)80116-X

[16] E. Lee and K. Aika, "Low-temperature methanol synthesis in liquid-phase with a Raney Nickelalkoxide system: Effect of Raney Nickel pretreatment and reaction conditions," J. Mol. Catal. A: Chem., vol. 141, pp. 241-248, 1999. doi:10.1016/S1381-1169(98)00267-2

[17] S. Ohyama, "Low-temperature methanol synthesis in catalytic systems composed of nickel compounds and alkali alkoxides in liquid phases," Appl. Catal. A, vol. 180, pp. 217-225, 1999. doi:10.1016/S0926-860X(98)00338-X 
[18] V. Palekar, H. Jung, J. Tierney and I. Wender, "Slurry phase synthesis of methanol with a potassium methoxide/copper chromite catalytic system," Appl. Catal. A, vol. 102, no. 1, pp. 1334, 1993. doi:10.1016/0926-860X(93)85152-F

[19] R. Sapienza, W. Slegeir, T. O'Hare and D. Mahajn, "Low temperature catalysts for methanol production". United States of America Patent US4614749A, 30 September 1986.

[20] S. Lee and A. Sardesai, "Liquid phase methanol and dimethyl ether synthesis from syngas," Top. Catal., vol. 32, pp. 197-207, 2005. doi:10.1007/s11244-005-2891-8

[21] G. Chinchen, P. Denny, D. Parker, M. Spencer and D. Whan, "Mechanism of methanol synthesis from $\mathrm{CO}_{2} / \mathrm{CO} / \mathrm{H}_{2}$ mixtures over copper/zinc oxide/alumina catalysts: use of $14 \mathrm{C}$ labelled reactants," Appl. Catal., vol. 30, no. 2, pp. 333-338, 1987. doi:10.1016/S01669834(00)84123-8

[22] G. Olah, A. Goeppert and G. Surya Prakash, "Chemical recycling of carbon dioxide to methanol and dimethyl ether: From greenhouse gas to renewable, environmentally carbon neutral fuels and synthetic hydrocarbons," J. Org. Chem., vol. 74, pp. 487-498, 2009. doi:10.1021/jo801260f

[23] O. Joo, K. Jung, I. Moon, A. Rozovskii, G. Lin, S. Han and S. Uhm, "Carbon dioxide hydrogenation to form methanol via a reverse-water-gas-shift reaction (the CAMERE Process)," Ind. Eng. Chem. Res., vol. 38, pp. 1808-1812, 1999. doi:10.1021/ie9806848

[24] J. Tremblay, "CO 2 as feedstock," Chem. Eng. News, vol. 86, p. 13, 2008.

[25] Carbon Recycling International, "World's largest $\mathrm{CO}_{2}$ methanol plant," [Online]. Available: http://carbonrecycling.is/george-olah/. [Accessed 16 August 2017].

[26] L. Fan, Y. Sakaiya and K. Fujimoto, "Low-temperature methanol synthesis from carbon dioxide and hydrogen via formic ester," Appl. Catal. A, vol. 180, pp. L11-L13, 1999. doi:10.1016/S0926-860X(98)00345-7

[27] B. Xu, R. Yang, F. Meng, P. Reubroucharoen, T. Vitidsant, Y. Zhang, Y. Yoneyama and N. Tsubaki, "A new method of low temperature methanol synthesis," Catal. Surv. Asia, vol. 13, pp. 147-163, 2009. doi:10.1007/s10563-009-9075-7

[28] R. Yang, Y. Fu, Y. Zhang and N. Tsubaki, "In situ DRIFT study of low-temperature methanol synthesis mechanism on $\mathrm{Cu} / \mathrm{ZnO}$ catalysts from $\mathrm{CO}_{2}$-containing syngas using ethanol promoter," J. Catal., vol. 228, no. 1, pp. 23-35, 2004. doi:10.1016/j.jcat.2004.08.017

[29] R. Yang, Y. Zhang and N. Tsubaki, "Dual catalysis mechanism of alcohol solvent and $\mathrm{Cu}$ catalyst for a new methanol synthesis method," Catal. Commun., vol. 6, no. 4, pp. 275-279, 2005. doi:10.1016/j.catcom.2005.01.008

[30] N. Tsubaki, M. Ito and K. Fujimoto, " A new method of low-temperature methanol synthesis," J. Catal., vol. 197, pp. 224-227, 2001. doi:10.1006/jcat.2000.3077

[31] J. Zeng, K. Fujimoto and N. Tsubaki, "A new low-temperature synthesis route of methanol: Catalytic effect of the alcoholic solvent," Energy Fuels, vol. 16, pp. 83-86, 2002. doi:10.1021/ef0100395

[32] P. Reubroycharoen, T. Yamagami, T. Vitidsant, Y. Yoneyama, M. Ito and N. Tsubaki, "Continuous low-temperature methanol synthesis from syngas using alcohol promoters," Energy Fuels, vol. 17, pp. 817-823, 2003. doi:10.1021/ef020240v

[33] C. Huff and M. Sanford, "Cascade catalysis for the homogeneous hydrogenation of $\mathrm{CO}_{2}$ to methanol," J. Am. Chem. Soc., vol. 133, pp. 18122-18125, 2011. doi:10.1021/ja208760j

[34] Y. Chen, S. Choi and L. Thompson, "Low-temperature $\mathrm{CO}_{2}$ hydrogenation to liquid products via a heterogeneous cascade catalytic system," ACS Catal., vol. 5, pp. 1717-1725, 2015. doi: $10.1021 / \operatorname{cs} 501656 x$

[35] T. Turek and D. Trimm, "The catalytic hydrogenolysis of esters to alcohols," Catal. Rev.: Sci. Eng., vol. 36, pp. 645-683, 1994. doi:10.1080/01614949408013931 
[36] M. Sahibzada, I. S. Metcalfe and D. Chadwick, "Methanol synthesis from $\mathrm{CO} / \mathrm{CO}_{2} / \mathrm{H}_{2}$ over $\mathrm{Cu} / \mathrm{ZnO} / \mathrm{Al} 2 \mathrm{O} 3$ at differential and finite conversions," J. Catal., vol. 174, pp. 111-118, 1998. doi:10.1006/jcat.1998.1964

[37] O. Martin and J. Pérez-Ramírez, "New and revisited insights into the promotion of methanol synthesis catalysts by $\mathrm{CO}_{2}$," Catal. Sci. Technol., vol. 3, pp. 3343-3352, 2013. doi:10.1039/C3CY00573A

[38] R. Struis, S. Stucki and M. Wiedorn, "A membrane reactor for methanol synthesis," J. Membr. Sci., vol. 113, pp. 93-100, 1996. doi:10.1016/0376-7388(95)00222-7

[39] F. Gallucci, L. Paturzo and A. Basile, "An experimental study of $\mathrm{CO}_{2}$ hydrogenation into methanol involving a zeolite membrane reactor," Chem. Eng. Process., vol. 43, pp. 1029-1036, 2004. doi:10.1016/j.cep.2003.10.005

[40] J. van Bennekom, R. Venderbosch, J. Winkelman, E. Wilbers, D. Assink, K. Lemmens and H. Heeres, "Methanol synthesis beyond chemical equilibrium," Chem. Eng. Sci., vol. 87, pp. 204208, 2013. doi:10.1016/j.ces.2012.10.013

[41] M. Bos And D. Brilman, "A novel condensation reactor for efficient CO2 to methanol conversion for storage of renewable electric energy," Chem. Eng. J., vol. 278, pp. 572-532, 2015. doi:10.1016/j.cej.2014.10.059

[42] M. Malone and M. Doherty, "Reactive distillation," Ind. Eng. Chem. Res., vol. 39, pp. 39533957, 2000. doi:10.1021/ie000633m

[43] J. Allison, H. Wright, T. Harkins and D. Jack, "Use of catalytic distillation reactor for methanol synthesis". United States of America Patent US 6,723,886 B2, 20 April 2004.

[44] S. Srinivas, R. Malik and S. Mahajani, "Feasibility of reactive distillation for Fischer-Tropsch synthesis," Ind. Eng. Chem. Res., vol. 47, pp. 889-899, 2008. doi:10.1021/ie071094p

[45] M. Bayat, Z. Dehghani, M. Hamidi and M. Rahimpour, "Methanol synthesis via sorptionenhanced reaction process: Modeling and multi-objective optimization," J. Taiwan Inst. Chem. Eng., vol. 45, no. 2, pp. 481-494, 2014. doi:10.1016/j.jtice.2013.06.013

[46] I. Illiuta, M. Illiuta and F. Larachi, "Sorption-enhanced dimethyl ether synthesis-Multiscale reactor modeling," Chem. Eng. Sci., vol. 66, no. 10, pp. 2241-2251, 2011. doi:10.1016/j.ces.2011.02.047

[47] J. Keuler, L. Lorenzen and S. Miachon, "The dehydrogenation of 2-butanol over copper-based catalysts: optimising catalyst composition and determining kinetic parameters," Appl. Catal., A, vol. 218, pp. 171-180, 2001. doi:10.1016/S0926-860X(01)00639-1

[48] S. Mostafa, J. Croy, H. Heinrich and B. Roldan Cuenya, "Catalytic decomposition of alcohols over size-selected Pt nanoparticles supported on $\mathrm{ZrO}_{2}$ : A study of activity, selectivity, and stability," Appl. Catal., A, vol. 366, pp. 353-362, 2009. doi:10.1016/j.apcata.2009.07.028

[49] R. Yang, X. Yu, Y. Zhang, W. Li and N. Tsubaki, "A new method of low-temperature methanol synthesis on $\mathrm{Cu} / \mathrm{ZnO} / \mathrm{Al}_{2} \mathrm{O}_{3}$ catalysts from $\mathrm{CO} / \mathrm{CO}_{2} / \mathrm{H}_{2}$," Fuel, vol. 87, pp. 443-450, 2008. doi:10.1016/j.fuel.2007.06.020

[50] N. Tsubaki, J. Zeng, Y. Yoneyama and K. Fujimoto, "Continuous synthesis process of methanol at low temperature from syngas using alcohol promoters," Catal. Commun., vol. 2, pp. 213-217, 2001. doi:10.1016/S1566-7367(01)00039-5

[51] W. Teo and D. Ruthven, "Adsorption of water from aqueous ethanol using 3-Å molecular sieves," Ind. Eng: Chem. Process Des. Dev., vol. 25, no. 1, pp. 17-21, 1986. doi:10.1021/i200032a003

[52] T. Kandemir, F. Girgsdies, T. Hansen, K. Liss, I. Kasatkin, E. Kunkes, G. Wowsnick, N. Jacobsen, R. Sclögl, and M. Behrens, "In Situ Study of Catalytic Processes: Neutron Diffraction of a Methanol Synthesis Catalyst at Industrially Relevant Pressure," Angew. Chem. Int. Ed., vol. 52, pp. 5166-5170, 2013 
[53] J. Sloczynski, R. Grabowski, A. Kozłowska, P. K. Olszewski and J. Stoch, "Reduction kinetics of $\mathrm{CuO}$ in $\mathrm{CuO} / \mathrm{ZnO} / \mathrm{ZrO}_{2}$ systems," Phys. Chem. Chem. Phys., vol. 5, pp. 4631-4640, 2003. doi:10.1039/b306132a

[54] J. Grunwaldt, A. Molenbroek, N. Topsøe, H. Topsøe, and B. Clausen, "In Situ Investigations of Structural Changes in Cu/ZnO Catalysts," J. Catal., vol. 194, pp. 452-460. 2000. doi:10.1006/jcat.2000.2930

[55] P. Hansen, J. Wagner, S. Helveg, J. Rostrup-Nielsen, B. Clausen and H. Topsøe, "AtomResolved Imaging of Dynamic Shape Changes in Supported Copper Nanocrystals," Science, vol. 295, pp. 2053-2055, 2002 doi:10.1126/science.1069325

[56] T. Lunkenbein, F. Girgsdies, T. Kandemir, N. Thomas, M. Behrens, R. Schlögl and E. Frei, "Bridging the Time Gap: A Copper/Zinc Oxide/Aluminum Oxide Catalyst for Methanol Synthesis Studied under Industrially Relevant Conditions and Time Scales," Angew. Chem., vol. 128, pp. 12900-12904, 2016 doi:10.1002/anie.201603368

[57] Y. Jeong, I. Kim, J. Kang, H. Jeong, J. Park, J. Park and J. Jung, "Alcohol-assisted low temperature methanol synthesis from syngas over $\mathrm{Cu} / \mathrm{ZnO}$ catalysts: Effect of $\mathrm{pH}$ value in the co-precipitation step," J. Mol. Catal. A: Chem., vol. 400, pp. 132-138, 2015 doi:10.1016/j.molcata.2015.01.008

[58] F. Arena, G. Mezzatesta, G. Zafarana, G. Trunfio, F. Frusteri and L. Spadaro, "Effects of oxide carriers on surface functionality and process performance of the $\mathrm{Cu}-\mathrm{ZnO}$ system in the synthesis of methanol via $\mathrm{CO}_{2}$ hydrogenation," J. Catal., vol. 300, pp. 141-151, 2013. doi:10.1016/j.jcat.2012.12.019 